\section{Intensity of Cosmic Radiation in the High Atmosphere}

ON Aug. 12, I succeeded in measuring the intensity of cosmic radiation in the high atmosphere, at air pressures down to $22 \mathrm{~mm}$. of mercury, by means of two rubber balloons and a self-registering electrometer. The electrometer was working on the same principle

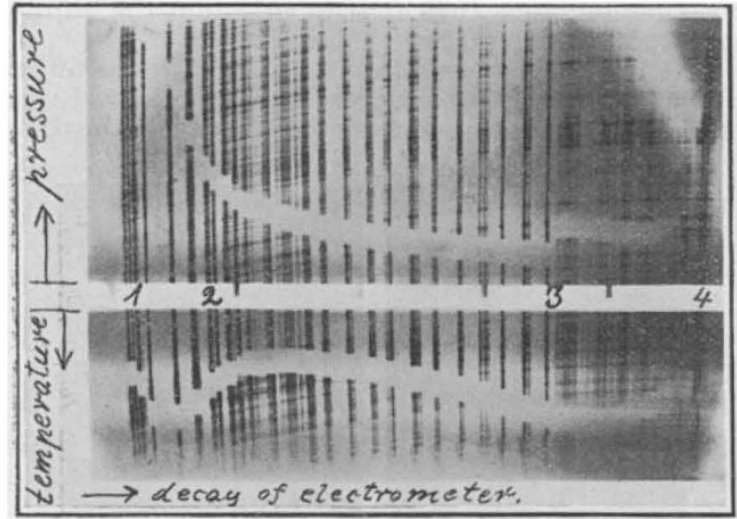

FIG. 1.

as that used for the investigations in Lake Constance. ${ }^{1}$ The position of an electrometer wire is photographed every four minutes on a fixed photographic plate. The volume of the ionisation chamber was $2 \cdot 1$ litres, the thickness of its walls was $0.5 \mathrm{~mm}$. The air pressure outside and temperature within the apparatus were

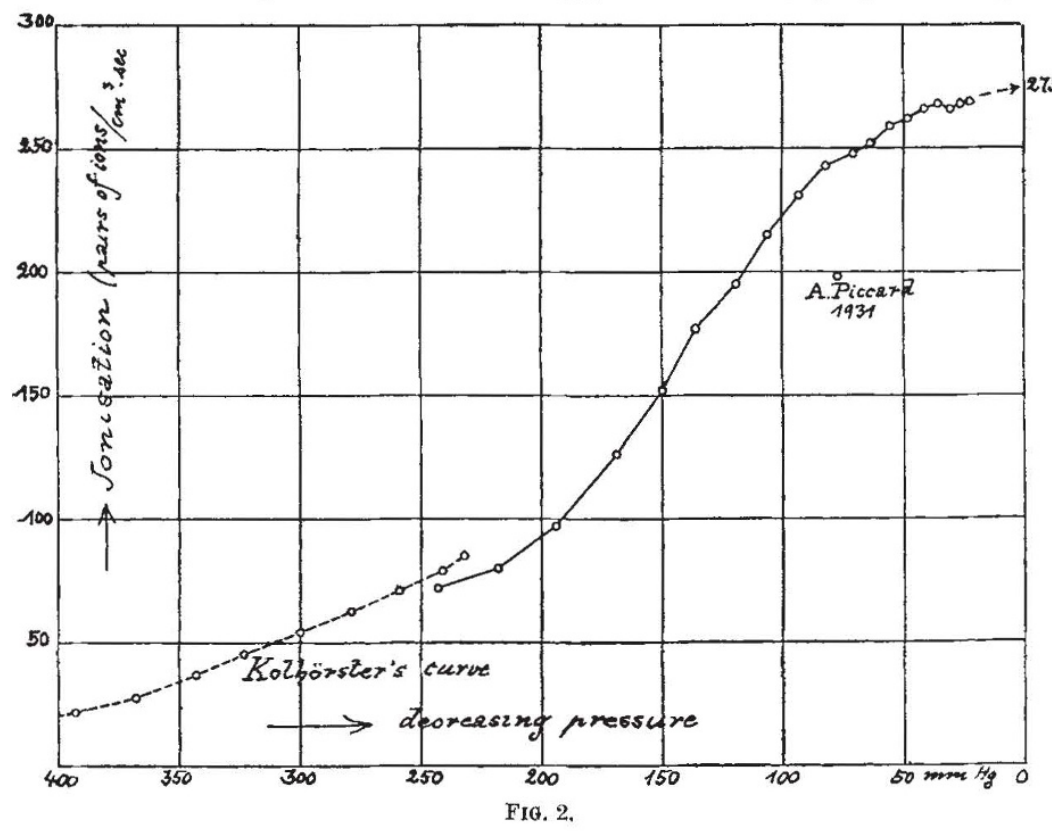

measured simultaneously with the electric tension by limiting the length of the wire pictures by an aneroid on one side and by a bimetallic lamella on the other. The apparatus was protected against the low air temperature in the stratosphere by a case of 'Cellophane', which catches the sun's rays like a 'forcing-house'. Therefore the temperature inside the apparatus only varied between $+15^{\circ}$ and $+37 \mathrm{C}^{\circ}$.

Fig. 1 is a reproduction of the results obtained on the photographic plate. At point 1 the apparatus begins to operate, between points 2 and 3 the tension is measured every 4 minutes, after 3 one of the balloons explodes, point 4 shows the landing. Between 2 and 3 the air pressure (upper limit of the wire photographs) varies from 243 to $22 \mathrm{~mm}$. of mercury.

Fig. 2 shows the results from this plate together with the end of the corresponding curve of Kolhörster and the value obtained by $A$. Piceard in 1931.2 The intensity $I$ of the cosmic radiation ( $I=$ pairs of ions per cm. ${ }^{3}$ sec.) is given as a function of the decreasing air pressure (in $\mathrm{mm}$. of mercury). The following results may be derived from this curve :

(1) Below $150 \mathrm{~mm}$. mercury (that is, above a height of about $12 \mathrm{~km}$.) the intensity of cosmic radiation increases less rapidly as one approaches the end of the atmosphere.

(2) At lower pressures the intensity approaches rapidly its highest value. Therefore it is possible to extrapolate the intensity of radiation at its entrance in the atmosphere. One gets a preliminary value of $275 I$., provided that the intensity does not pass through a maximum value and decrease again at greater heights. This might be the case in consequence of result (3).

(3) The cosmic radiation saturates itself with secondary radiation after having entered the atmosphere. If it remained a mere primary radiation, its intensity would decrease much more rapidly at great heights, and the curve of Fig. 2 would have no point of inflec. tion.

(4) There seerns to be no $\gamma$-radiation of the common radioactive bodies in outer space. Otherwise it would give rise to a new increase of intensity in the highest parts of the curve, as about 20 per cent of the common $\gamma$-rays would pass through a layer of air correspond. ing to a pressure of $22 \mathrm{~mm}$. of mercury.

Supposing air temperature is constant and equal to $0^{\circ} \mathrm{C}$., a height of $28 \mathrm{~km}$. corresponds to a pressure of $22 \mathrm{~mm}$. of mercury.

A more detailed report of the investigation will be published shortly in Die Naturwissenschaften.

\section{E. REgener.}

Physical Institute of the Technical High Sehool, Stuttgart, Aug. 20.

1 Z. Phys., 74, 433; 1932.

Naturwissenschaften, Aug. 5, 1932.

\section{The a-Rays of Ionium}

THE differential method of Lord Rutherford for counting $\alpha$. particles may of course be used, and with great advantage, for the measurement of the ionisa. tion current. It gives the dif. ferential of the ordinary Bragg curve, the variation of the ionisa. tion from element to element of distance, rather than the total ionisation for the element.

I have constructed an apparatus for this purpose capable of considerable accuracy, and the results so far obtained in calibrating it with the $\alpha$-rays of polonium and ionium have features difficult to in. terpret. It has three ionisation chambers, $1.85 \mathrm{~mm}$. deep, separated by aluminium leaf equivalent in stopping power to about $1 \mathrm{~mm}$. of air, the one nearest the source being a guard chamber, and the current

No. 3279 , VoL. 130] 